\title{
Del familisterio al condensador social. El colectivo Chollín como arquetipo moderno ${ }^{1}$.
}

\author{
From a familystry to a social condenser. \\ The Chollin Collective as a modern archetype.
}

$\triangle$ Palabras clave/ Conjuntos habitacionales, arquitectura moderna, tipología habitacional, arquitectura chilena

$\Delta$ Keywords/ Housing lots, modern architecture, housing typology, Chilean architecture

$\triangle$ Recepción/ 17 septiembre 2014

$\triangle$ Aceptación/ 14 enero 2015

RESUMEN/ El colectivo Chollín (Ramón Acuña, Alberto Risopatrón, Mario Valdivieso, 1943-1950) de la Carbonífera Schwager, poseedor de un lenguaje moderno inédito y un tamaño inusual, se incorpora a la ciudad industrial de Puchoco, Schwager, declarada zona típica en 2010, al sur de Chile. Este trabajo consigna que incorpora al menos tres referentes de la vanguardia arquitectónica, Los dos primeros de orden ideológico-formal: el interés reformador de las ciudades utópicas del siglo XIX y los intereses progresistas de la vanguardia socialista del siglo XX; y el tercero de orden experiencial: Los fenómenos perceptuales del promenade arquitectural. Su organización arquitectónica originó un conjunto mixto e innovador, desconocido por la historiografía latinoamericana. Su diseño ha fomentado las relaciones comunitarias, acentuando la experiencia sobre la pertenencia y la identidad, aspectos que ratifican su incorporación al patrimonio moderno. ABSTRACT/ The Chollín Collective (Ramón Acuña, Alberto Risopatrón, Mario Valdivieso, 1943-1950) of Schwager coal company, featuring an unprecedented modern language and an unusual size, becomes part of the industrial city of Puchoco, Schwager, south of Chile, declared a typical site in 2010. This work reveals that it introduces at least three references of the architectonic avant-garde, the first two of a formal-ideological nature: the reforming interest of the utopian cities of the nineteenth century, and the progressive interests of the socialist avant-garde of the twentieth century; and the third one of an experiential nature: the perceptual phenomena of the architectural promenade. Its architectonic organization led a mixed and innovative set, unknown until then to the Latin-American historiography. Its design has promoted community relations, stressing the experiences about ownership and identity, aspects that ratify its introduction to the modern heritage.

Dr. Pablo Fuentes Hernández. Arquitecto Universidad del Bío-Bío, Concepción, Chile.

Doctor en Arquitectura, Universidad

Politécnica de Madrid, España.

Profesor Asociado, Departamento de

Diseño y Teoría de la Arquitectura, Facultad de Arquitectura, Construcción y Diseño,

Universidad del Bío-Bío, Concepción, Chile. pfuentes@ubiobio.cl
1. INTRODUCCIÓN. A comienzos del

siglo XX el ideario de la modernidad arquitectónica, específicamente aquellos aspectos que se interesaban por el bienestar social, los problemas urbanos y la democratización del bienestar, habían penetrado en Chile con mayor facilidad que aquellos que divulgaban las nuevas formas arquitectónicas y los avances tecnológicos. Ello explica el notorio interés cultural sobre el problema habitacional en los albores de esta centuria y, por el contrario, la escasa capacidad práctica para responder a este conflicto con una arquitectura calificada. En 1936 el Estado creó la Caja de Habitación Popular, la que introdujo ideas y formas sobre la racionalización arquitectónica en todo el territorio.

El 24 de enero de 1939, un devastador terremoto asoló las zonas de Chillán y Concepción, al sur del país. El sector habitacional de la zona minera se vio muy afectado en sus edificaciones (Astorquiza, 1952)2. La reconstrucción habitacional concentró adelantos funcionales y

formales que demandaba la modernización residencial.

En los años 40 la Compañía Carbonífera y de Fundición Schwager, empresa particular, auspició el surgimiento del colectivo Chollín, desconocido por la historiografía nacional ${ }^{3}$.

La hipótesis de este trabajo es que el edificio aunó dos voluntades ideológicas: una que acogía a la familia tradicional y la otra de la vanguardia colectivista que, inspirada en el socialismo utópico del siglo XIX y en los condensadores sociales de comienzos del siglo XX, aspiraba a una transformación social del proletariado y a una renovación espacial de su hábitat residencial.

El objetivo general es revelar las alternativas proyectuales del edifico Chollín como manifiesto de las vicisitudes de la vanguardia arquitectónica y habitacional, propias de la consolidación de la arquitectura moderna en Chile. 


\section{PUCHOCO, CIUDAD INDUSTRIAL. TRANSFORMACIÓN DEL PAISAJE HABITACIONAL MINERO. El edificio}

\section{Chollín fue situado en el sector Puchoco} Schwager, al extremo norte de la bahía de Coronel ${ }^{4}$, donde se había desarrollado una ciudad campamento originada por el descubrimiento de yacimientos carboníferos en 1849 por don Jorge Rojas. A partir de 1920 la compañía erigió allí una serie de pabellones habitacionales y equipamientos que consolidaron la ciudad industrial (imagen 1) ${ }^{5}$. El multifamiliar, si bien alteró las dimensiones arquitectónicas y tipológicas a usanza hasta los años 40 en Puchoco, reinterpretó las características colectivistas y programáticas de la colonia industrial, consiguiendo una total inserción en ella. Hubo tres razones para emplazar el nuevo edificio: la primera era que los pabellones residenciales existentes habían sufrido serios daños con el terremoto de 1939, haciendo urgente su reemplazo por unas estructuras sólidas.
La segunda era que la alta demanda mundial de cobre generada por la II Guerra Mundial exigía gran cantidad de carbón para su producción. En este marco, la Compañía Mina Puchoco contempló entre 1944 y 1956 la construcción del Pique Arenas Blancas a $1.500 \mathrm{~m}$. al norte del enclave urbano de Puchoco. Esta instalación demandó, para su construcción, gran cantidad de obreros, y para la explotación de los yacimientos una gran cantidad de mineros, quienes originaron una alta demanda habitacional en el área, incrementada por el terremoto de 1939

La tercera, es que en el contexto de la recuperación económica posbélica de los 40, la consunción del modelo de ciudad industrial en la industria carbonífera usualmente restringido a pabellones de viviendas de dos niveles carentes de servicios sanitarios básicos-, era sustituido por arquetipos habitacionales a gran escala, recientemente elaborados por el Estado chileno en las zonas mineras del norte del país ${ }^{6}$. El colectivo Chollín (19431950) fue una operación arquitectónica extraordinaria que promovía un esquema único de organización social. Consignado para trabajadores del carbón, iniciativa benefactora de la industria, fue una edificación de impulso privado sin precedentes en el escenario habitacional del pais

El Chollín, si bien presenta un lenguaje arquitectónico inusualmente extendido, su naturaleza se consigna como un fragmento cabalmente incorporado a la colonia minera de Puchoco (imagen 2).

Sus arquitectos fueron Ramón Acuña, Alberto Risopatrón y Mario Valdivieso, quienes recibieron el mandato de la Carbonifera Schwager para diseñar este colectivo habitacional para mineros y empleados, en un período identificado por el afianzamiento de la arquitectura moderna. Hubo razones fundadas para encargar una alternativa eficaz y moderna: que en los años 40 el proceso de modernización carbonífero se consolidaba en la región; que la población había aumentado en la zona7; y que los estándares habitacionales se modernizaban en Chile. El edificio Chollín fue situado borrando vetustos pabellones mineros y eclipsando una estrategia habitacional ya agotada. La obra se emplazó frente al mar Pacífico, cotejando su magnitud con la inmensidad del horizonte oceánico (imagen 3).

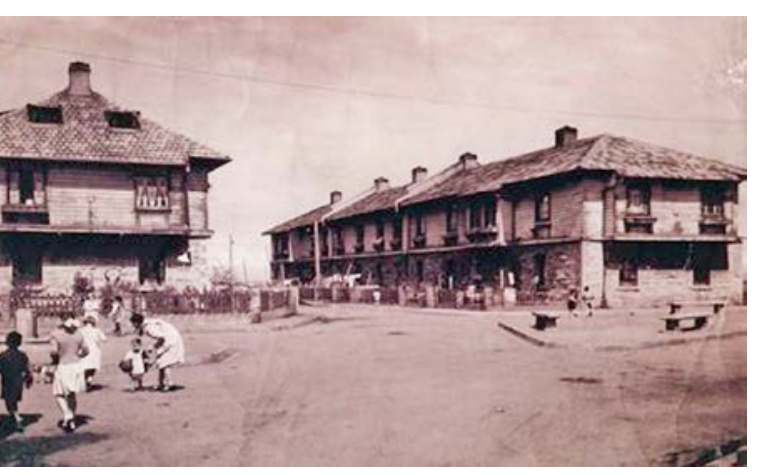

Imagen 1. Pabellones obreros, Puchoco (1945).

(fuente: Inostroza, Carlos. Schwager imágenes sociales inéditas.

Consejo de la Cultura y las Artes Región del Bío-Bío, 2010).

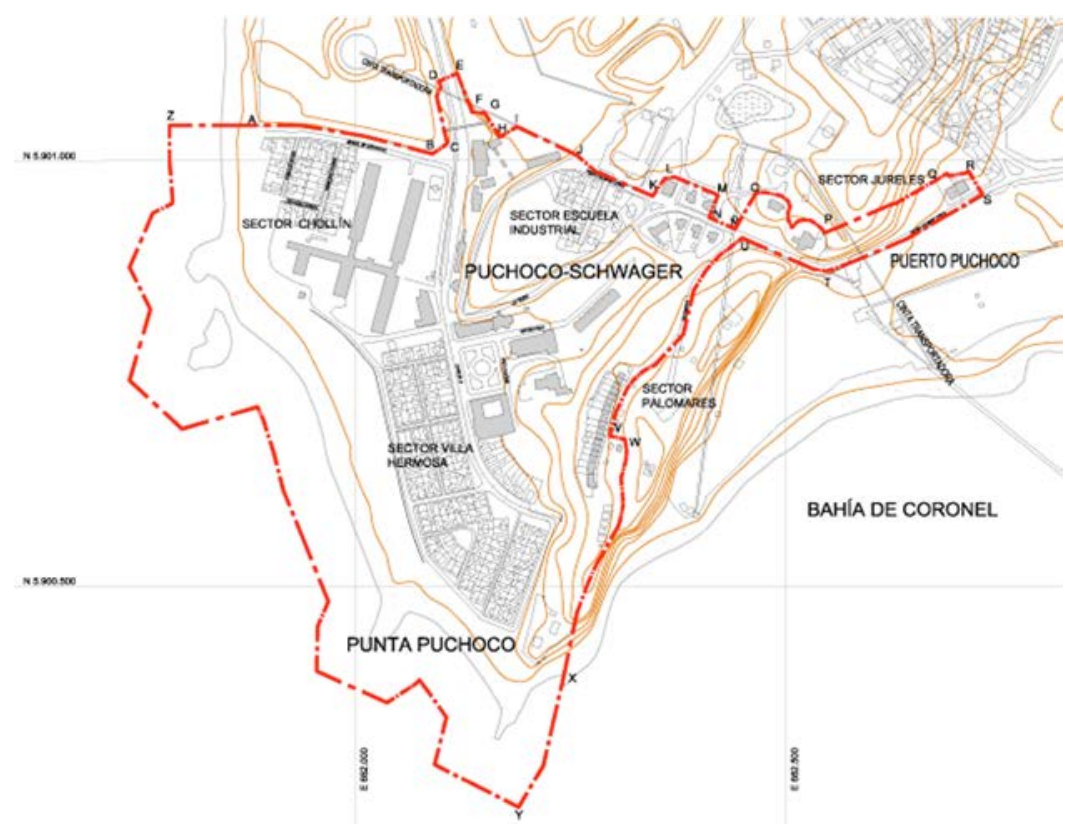

$50{ }^{4}$ El sitio de Punta Puchoco estaba originalmente parcelado en los sectores de Puchoco-Rojas, Puchoco-Délano y Puchoco-Schwager. Ver http://www.coronel.cl/2011/07/puchoco-schwager/ ${ }^{5}$ Ver Pérez, Leonel. "El barrio Puchoco en Schwager, cuando la industria construye paisaje cultural". Urbano, vol. 11, n 18, noviembre, 2008 , pp. 47-58. ${ }^{6}$ Se trata de los Colectivos para la Zona Norte de la Caja del Seguro Obrero en Antofagasta, Tocopilla, Arica, etc. 7 El censo de 1940 determinó que entre 1930 y 1940 la población de Coronel había aumentado de 20.632 a 28.027 hbts., es decir, un 35,8 \%, bastante más que en Lota que lo había hecho de 27.736 a
34.445 hbts.. es decir, un $24.1 \%$. 


\section{ARQUITECTURA DE UN DISEÑO HÍBRIDO. DILIGENCIAS DEL \\ PROYECTO. El Chollín consta de cinco}

bloques residenciales y otro para el

Apostolado Popular, lugar donde los moradores obtenían amparo y formación (imagen 4). Fue construido por etapas: la primera, de 1943, próxima al mar, consideró el Apostolado Popular, el edificio para obreros solteros y dos bloques de departamentos unifamiliares. La segunda, de 1950, otros dos bloques de departamentos unifamiliares, situados al oriente, junto al camino de acceso al conjunto.

Las unidades enlazadas por alargadas circulaciones, ocasionaron áreas de reunión y entretenimiento de extensiones espaciales hasta entonces inexploradas.

El complejo tiene 196 departamentos (176 unifamiliares y 20 de solteros) cuyo diseño consideró una trasposición de plantas iguales. Fue habitado diferenciando dos grandes grupos de moradores: las plantas $1^{\mathrm{a}}$ y $2^{\mathrm{a}}$, que demandaban menor esfuerzo para subir, fueron alojadas por empleados de la compañía; las plantas $3^{a}$ y $4^{a}$, con llegada más incómoda, fueron resididas por trabajadores con algún nivel de preparación técnica. Esta separación muestra una soterrada segregación obrera usual en los asentamientos mineros de la época. El complejo contempló dos tipos de bloques: los de departamentos unifamiliares y aquel para solteros. Los primeros, emplazados de norte a sur, tenían como eje estructurador un pasillo de circulación interior flanqueado por los departamentos. Son viviendas unifamiliares de 3 dormitorios, estar-comedor-cocina y un baño, ocupando unos $82 \mathrm{~m}^{2}$. Un balcón prolonga el estar al exterior. En la mitad del edificio se

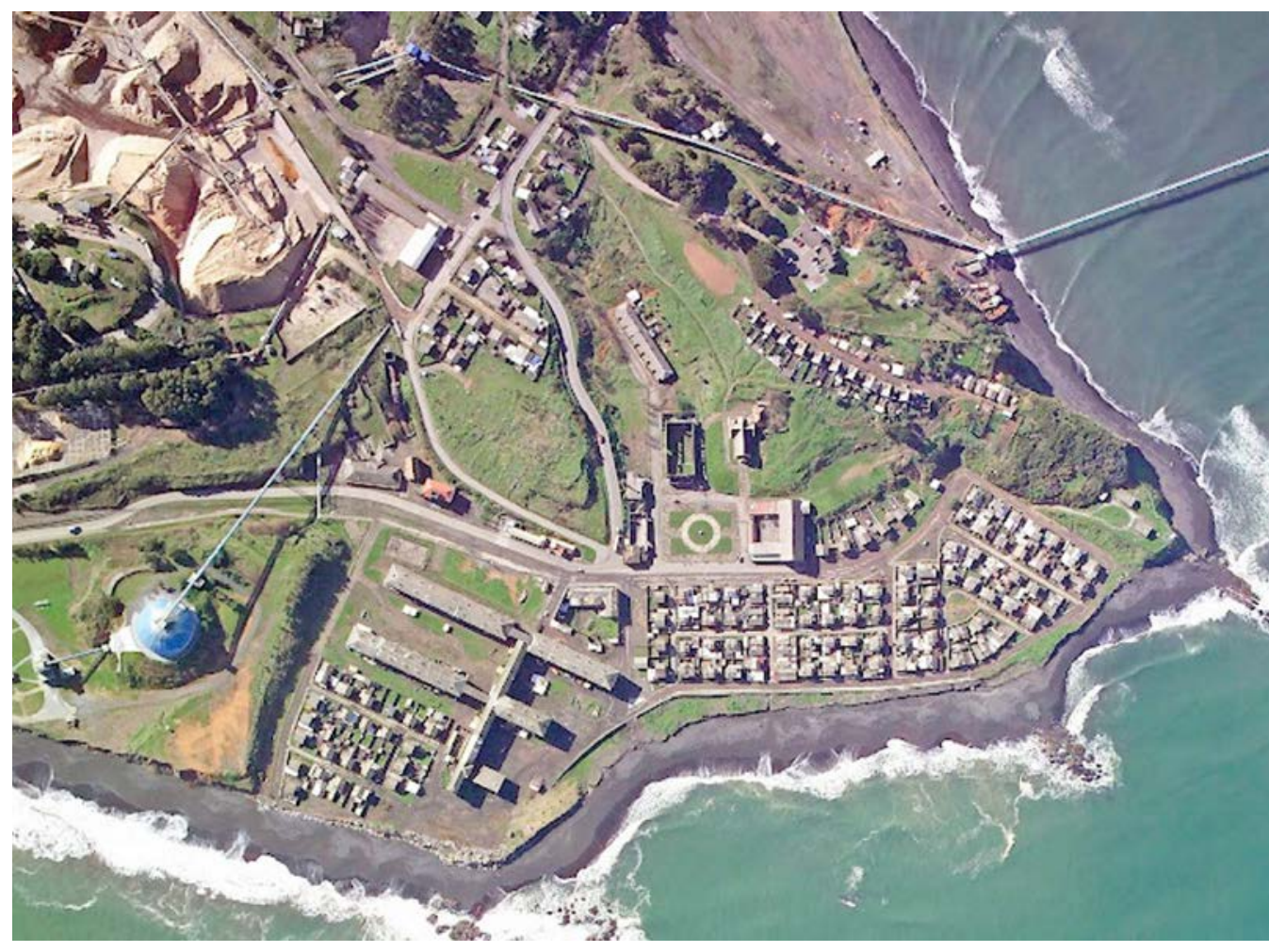

Imagen 3. El edificio Chollin, en Puchoco Schawger, frente al mar Pacifico (fuente: 3bp.blogspot.com)

concentran escaleras que conectan los cuatro niveles con los pasillos de cada planta, facilitando la llegada hasta las rampas, reiterando así la idea de recorrido continuo.

El segundo, para obreros solteros, situado de oriente a poniente, contiene módulos de planta libre de $156 \mathrm{~m}^{2}$, divididos en 16 cubículos individuales y 2 baños comunes en los extremos. Tiene un pasillo abierto al costado sur, protegido de la lluvia y del viento, que favorece el encuentro y permite el acceso a los módulos. Este corredor permite la contemplación de los patios al sur del complejo, lugar donde convergen juegos y actividades domésticas, y conecta con las rampas y el cuerpo del Apostolado. Un tercer volumen situado al sur poniente alberga el Apostolado Popular, que es un espacio en planta libre de dos niveles; el primero destinado a lavandería y el segundo, donde las pobladoras recibian capacitación y además lugar de comidas para los trabajadores solteros.
Los cruces de volúmenes originan un complejo que escinde al menos cuatro patios abiertos por uno o dos lados, más otras áreas exteriores que sirven para juegos, estacionamientos, garajes, etc Se contraponen en el conjunto dos expresiones, unas formas opacas que albergan la vida íntima de las viviendas y unos andamiajes transparentes que revelan las circulaciones públicas por las rampas de circulación. En esta oposición de resuelve el desenlace total del proyecto.

Concurren a este conjunto, diversas invariantes de la arquitectura moderna: la forma como resultado de un desarrollo funcional, la imposición de un lenguaje nuevo sobre un contexto ya edificado, el uso del hormigón armado y la incorporación del pasillo corredor y la rampa, como prototipo paradigmático de las circulaciones en promenade 8 . 
Imagen 4. Regulaciones de uso no determinan áreas para toda posible. Área gris oscuro sin regulación (fuente: elaboración propia. la superficie libre cuando la ocupación de suelo es la menor

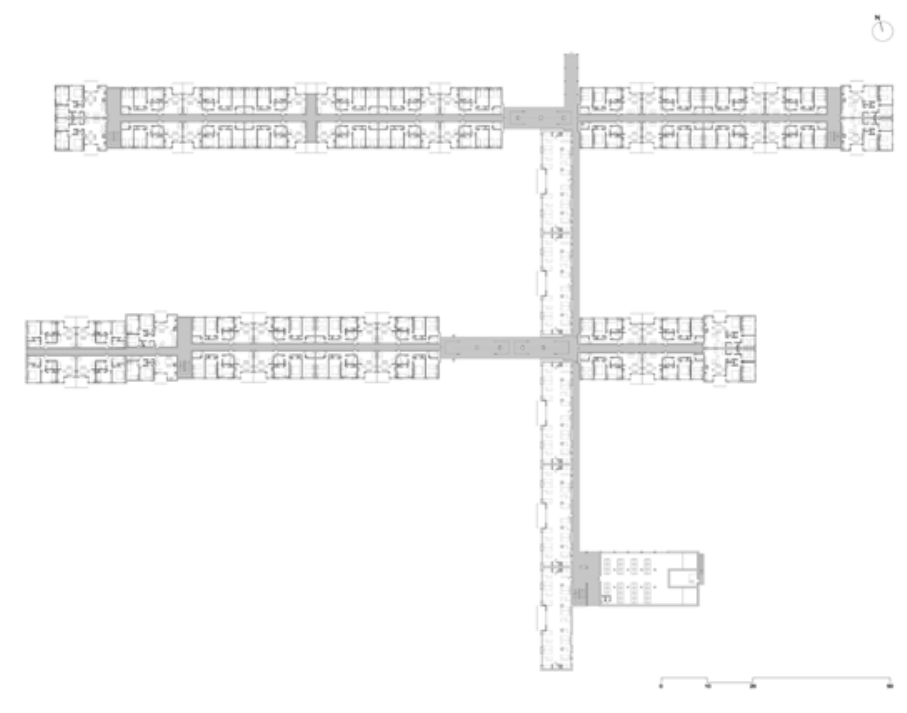

En lo funcional el edificio se organiza de acuerdo a grupos de solteros y familias tradicionales; dos grupos aptos para la convivencia y necesarios para la productividad industrial.

4. CITAS AL MODELO UTÓPICO. LA VIGILANCIA COMO ARGUMENTO

\section{COLECTIVISTA.}

los modelos utópicos del siglo XIX al concentrar en un solo edificio a una comunidad que desarrolla su vida coligada al funcionamiento industrial. Si bien su funcionamiento no alcanzó a establecer un modelo socioeconómico y productivo de inspiración socialista, incorpora un modo habitacional colectivo al amparo benefactor de una industria. El sentido comunitario se advierte en la medida que no hace grandes diferencias sociales sobre los grupos

habitacionales, en la protección que reciben los trabajadores sobre su vida doméstica y la compartición plena de las áreas comunes.
En lo formal, las referencias al modelo utópico se advierten sobre el tamaño de los edificios, su altura relativa, la conformación de grandes patios y la dependencia que sobre ellos hacen las circulaciones horizontales, las que son relevantes ya que actúan como calles elevadas que permiten el acceso a los departamentos, protegen de la intemperie y favorecen los encuentros. Es un arquetipo presente en la edificación paradigmática del socialismo utópico del s. XIX que ha servido para preservar el control social. Un ejemplo es el Falansterio (1843) de Victor Considérant, donde la calle galería va por las caras internas del edificio controlando los patios. Otro es el Familisterio de Guise (1877) de Jean Baptiste Godin, donde cada edificio rodea con sus pasillos un patio interior cubierto, fomentando el control social, y que en conjunto rodean una plaza central. En las rampas del Chollín, así como en el pasillo del edificio de solteros, la mirada alcanza un estado omnipresente y vigilante sobre los patios; se transforma en un medio para que unos y otros interactúen al cuidado y en beneficio de una colectividad de habitantes. La posibilidad multidireccional del control del espacio garantizaba la prudencia de las acciones. Congruentemente, esta experiencia basada en la custodia espacial sobre los comportamientos ajenos estaba influida por ideas sobre la educación moral del proletariado, factor consustancial al progreso y la modernidad.

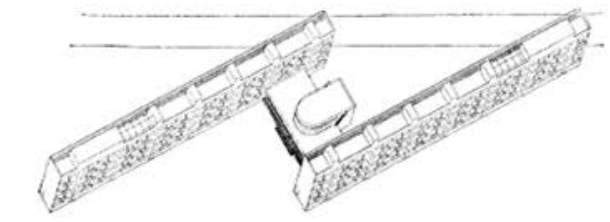

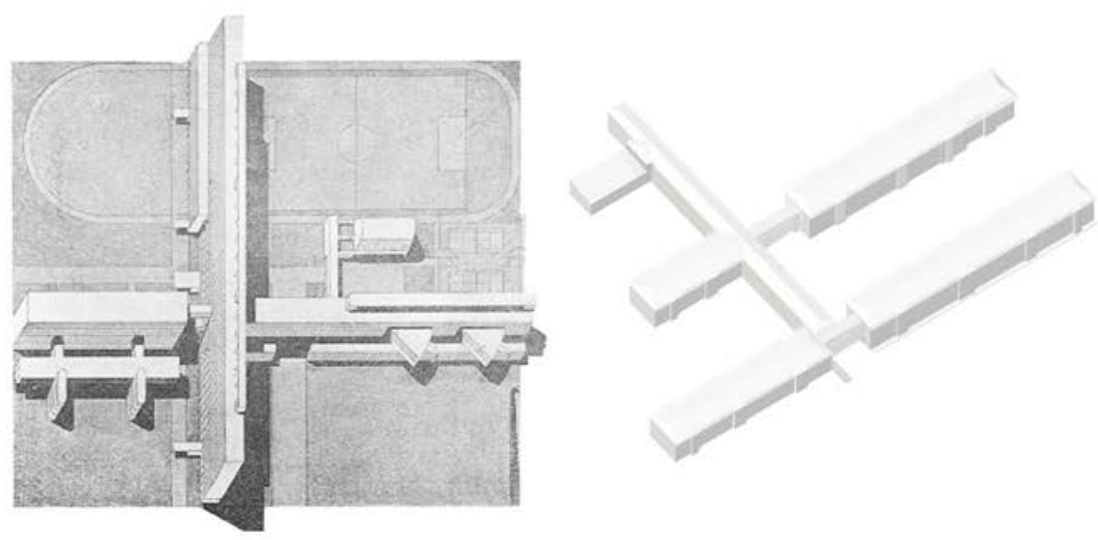

Imagen 5. Izquierda: Casa comuna tipo A (1928), arquitectos, M. Ginsburg. M. O. Bartshch, Pasternak, y V. Vladimirov. Centro: Casa comuna (1929), arquitectos, Bartshch y Vladimirov. Derecha: Edificio Chollin (1943-1950). Aratos.: Ramón Acuña, Alberto Rispatrón y Mario Valdivieso (fuente para imagen izquierda y centro: Teige, 2002; fuente para imagen derecha: el autor). 

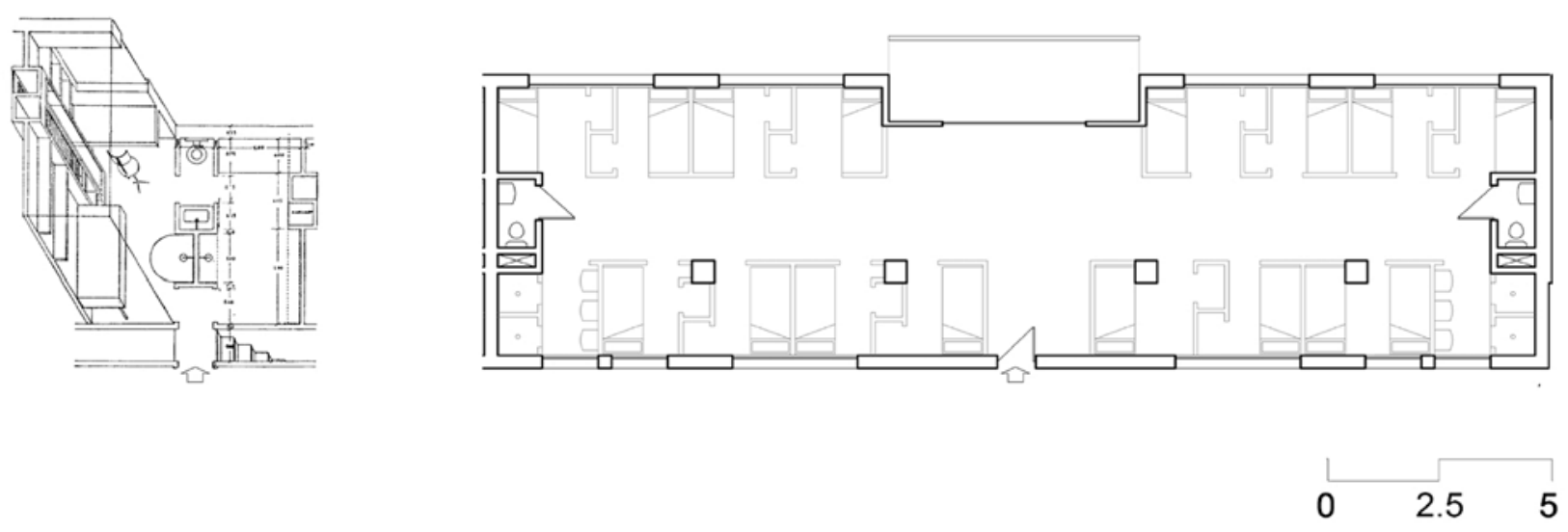

Imagen 6. Izquierda: cubiculo para soltero en Casa comuna (1929), arquietctos Bartshch y Vladimirov (fuente: Teige,2002). Derecha: departamento de solteros, Edificio Chollin (1943-1950), arquitectos Imagen 6. Izquierda: cubiculo para soltero en Casa comuna (1929), ara
Ramón Acuña, Alberto Risopatrón y Mario Valdivieso (fuente: el autor).

\section{APROXIMACIONES A LA} VANGUARDIA SOCIALISTA. El colectivo

Chollín es una mega estructura compuesta por dos modelos sociales de habitación y, en consecuencia, por dos tipos arquitectónicos diferentes. Uno responde al edificio de departamentos para la familia tradicional y el otro, al agrupamiento de habitáculos individuales en departamentos para obreros solteros, símbolo de un nuevo sistema social proletario promovido por las revoluciones políticas de inicios del siglo $X X^{9}$.

Acentúa esta idea que su inusual magnitud arquitectónica guarda parentesco formal e ideológico con la dom-komuna, la "casacomuna", un condensador social ruso que integraba viviendas con servicios colectivos y que representaba, según Karel Teige, una auténtica solución para la vivienda colectiva socialista. Se trata de edificios diseñados por arquitectos donde se repiten los nombres de Barshch, Vladimirov y Ginsburg, entre otros, proyectados entre 1928 y 1929. En esta definición, cabe la proclamación socialista y revolucionaria de un nuevo tipo humano determinado por una vida individual, en pro de una mejora trascendente de sus instintos y sentimientos. "(...) como una célula estandarizada el espacio para la vivienda de un individuo es transformado en su más auténtica forma por la cual cada habitante, con su preciosa libertad y paz espiritual, obtiene durante sus horas de descanso (Teige, 2002, p. 354).' Teige sostiene que la dom-komuna se trata de una comunidad autónoma, una estructura unificada para servir tanto a la vida individual como colectiva, cuyo diseño congregaba en un todo unificado elementos heterogéneos. Su énfasis estaba en los espacios colectivos y en consecuencia, debía procurar bajos costes y ahorro de espacio individual. Por el contrario, debía otorgar generosidad en los espacios sociales para nutrir un nuevo tipo de vida. La principal opción era oponerse al rascacielos americano, considerado como inadecuado para la nueva vida social y propio de un sistema capitalista.

En ese caso, la vivienda colectiva debía ser concebida como un complejo más grande que los edificios tradicionales. Para un ahorro máximo se evitaba el ascensor evitando una altura superior a cinco pisos. El uso de transportes mecánicos horizontales potenciaría las calles interiores y eventualmente edificios de cientos o miles metros de largo. Así, las viviendas colectivas eran esencialmente megaestructuras grandes de mediana altura.

Era, en síntesis, un modelo de organización socialista que amparaba las relaciones comunitarias, lo suficientemente virtuoso como para respaldar una respuesta arquitectónica con principios colectivistas Si se observa la longitud de sus barras habitacionales, la forma y posición de los servicios de apoyo, y el tipo de circulaciones y articulaciones, el edificio Chollín parece inspirado en la casa-comuna para el Comité para la Construcción Estatal (República Socialista Federativa Soviética de Rusia) de 1928 (M. Ginsburg, M. O. Bartshch, Pasternak y V. Vladimirov) y en la casa-comuna de 1929 (Bartshch y Vladimirov) (imagen 5). En sus plantas, las similitudes se advierten en el ancho de sus crujías y en el largo de sus cuerpos. Son semejantes, específicamente, en la proporción del espacio entre bloques respecto del edificio de 1928, y en el cruce y tensión de los cuerpos del de 1929. En todos los casos un cuerpo más corto ocupa los servicios de apoyo. Asimismo, las prolongadas circulaciones internas y externas ocupadas en los edificios soviéticos, aparecen incorporadas en el edificio chileno

Si se observan los cubículos para obreros solteros, cabe constatar que los del edificio ruso eran dobles, de modo que dos personas compartían un área común de servicios sanitarios. En el edificio chileno, no obstante, el baño ocupa una posición en los extremos del departamento, incluyendo inodoro, duchas y lavamanos aparte (imagen 6).

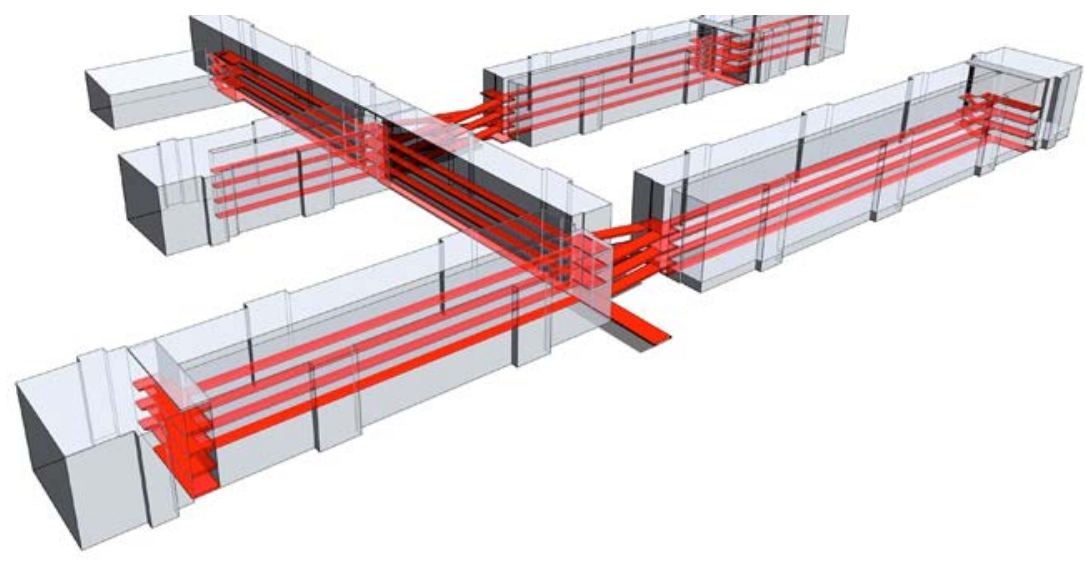




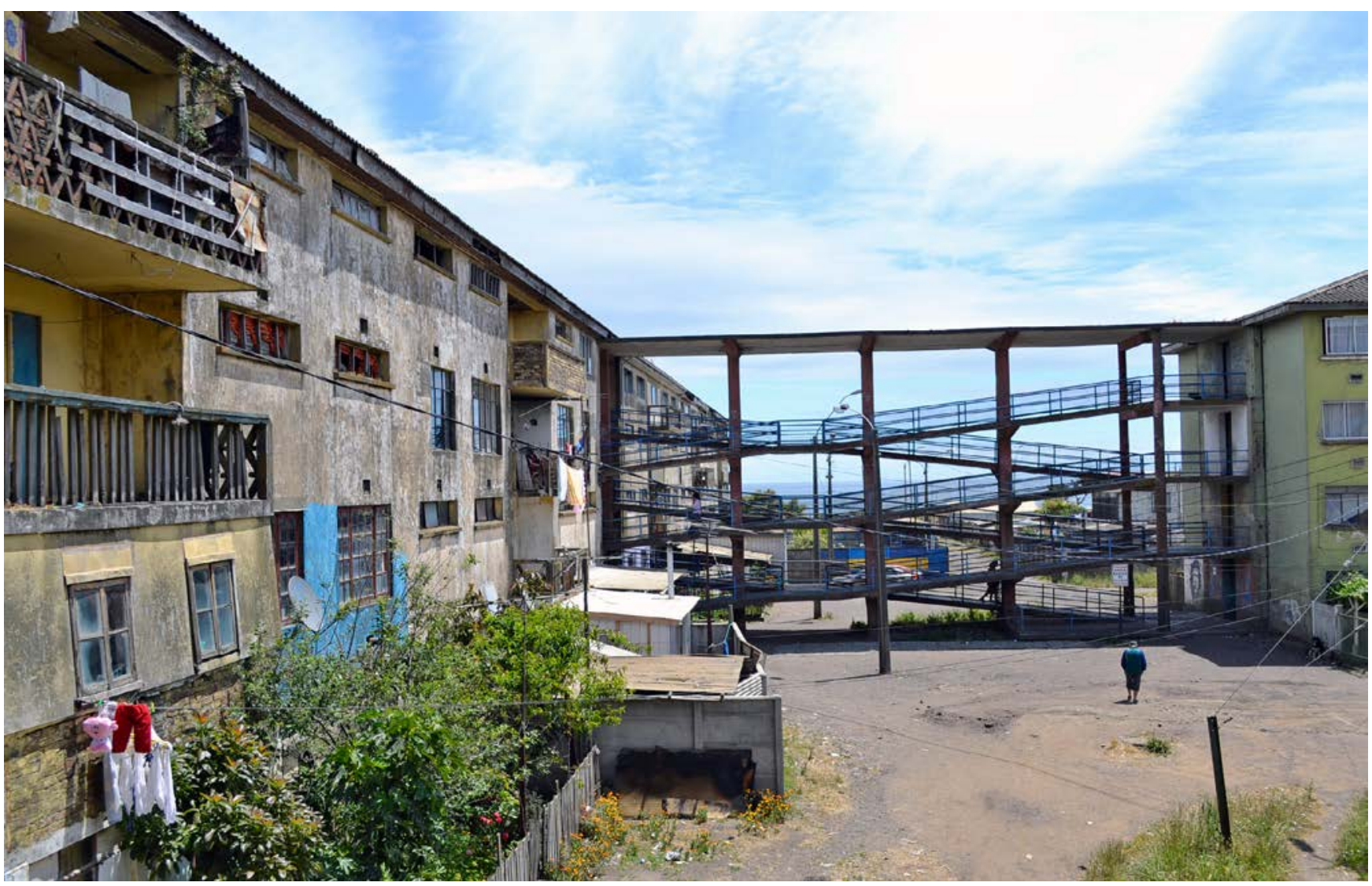

Imagen 8. Rampas del edificio Chollin (fuente: el autor)

\section{PASILLOS Y RAMPAS.}

\section{ARGUMENTOS PARA UN PROMENADE} ARQUITECTURAL.

habitacional tuvo un apoyo institucional decisivo en Chile, las circulaciones tuvieron especial atención. Los pasillos exteriores parecen tener referentes precisos en la arquitectura de Europa del Este de los años 20 y $30^{10}$, que eran edificios conocidos como "casa-balcón" o de "galería abierta", una tipología sistematizada para departamentos pequeños en proyectos a gran escala que favorecian la luz y el sol en los departamentos y la ventilación cruzada para los espacios habitables

Muchos edificios de la Caja del Seguro Obrero, liderada entonces por el arquitecto Luciano Kulczewski, habían incorporado corredores exteriores anexos a los cuerpos de habitación. El Colectivo San Eugenio (1934) y los Colectivos para la Zona Norte desarrollados desde 1939 constituyen un antecedente inmediato al edificio Chollín (Galaz-Mandacovic, 2011). La tipología era coetánea a dos conjuntos habitacionales de la Caja de la Habitación Popular en

- Concepción: la población Lorenzo Arenas y la Bío-Bío, ambas de 1942
La estructura de circulaciones del edificio Chollín favorece el tránsito horizontal. Se trata de una corredera de unos $2.200 \mathrm{~m}$. en total, que relaciona rampas, pasillos interiores, exteriores y escaleras, permitiendo una secuencia inagotable de itinerarios (imagen 7).

Las rampas situadas como conectores neurálgicos, proyectadas para trasladar el carbón que proveía las cocinas de los departamentos, componen un artilugio de asombrosa modernidad formal que evidencian el deseo por albergar el encuentro social y el control visual. Unas veces hacen de miradores que fomentan la atención sobre patios comunes, otras brindan la contemplación del panorama y admiten el roce comunitario.

Las rampas tenían antecedente inmediato en los Colectivos de la Zona Norte ya mencionados. Allí eran unos cuerpos parcialmente exteriores, perpendiculares a la longitud del bloque como único medio de acceso a sus diferentes niveles ${ }^{12}$

Para el Chollín, las rampas fueron escogidas como principal medio de circulación vertical, usadas como cintas de sutura entre los cuerpos del sector sur y norte. Cuando irrumpen con su rellano en el cuerpo de departamentos de solteros, este punto se revela como un nodo distribuidor que facilita las conexiones inmediatas con pasillos interiores y exteriores de los cuerpos adyacentes. El esqueleto de la rampa se expone al exterior como un cuerpo asimétrico.

Las rampas de hormigón articulan en medias alturas a los cuerpos del sur y del norte. Conforman un sistema de circulación vertical cubierto, abierto al oriente y al poniente. Son estructuras que admiten el traspaso de las vistas al cielo, al mar y al entorno circundante (imagen 8). Actúan como miradores elevados y sus tramos promueven la detención, el encuentro social y la contemplación del paisaje.

Su implementación obedecería al tráfico de discapacitados, numerosos en las faenas mineras, y al tránsito de combustibles para calderas y cocinas. Sus pendientes facilitaban el desplazamiento de muebles, alimentos y utensilios propios de un complejo habitacional de alta densidad. De uno u otro modo, las rampas del edificio eran un sistema análogo a las galerías de explotación carbonífera. 
El sistema de circulaciones a través de rampas, pasillos y escaleras supone el desarrollo de un promenade arquitectónico ininterrumpido, continuo y progresivo, que admite avanzar, retroceder, extraviarse y reencontrarse, habilitado para articular todas las barras y niveles, mudando de bloques, direcciones y niveles a voluntad. El privilegio que ofrecen sus alternativas visuales son una lección del promenade en Chile.

"La rampa facilitará una ascensión despreocupada que ha de favorecer el despliegue encadenado de experiencias perceptivas, un continuum espacio-tiempo.
(...) Así pues, la rampa es el elemento primordial en la percepción del espacio moderno, la cuarta dimensión inherente a la promanade architecturale (...)" (Baltanás, 2005, pp. 6 y 7).

Como una narración continua e ininterrumpida del espacio, propia del travelling cinematográfico, presenta perspectivas y cerramientos, tensiones y fugas, paneos, avances y giros, percibiendo transparencias y opacidades, claridad y oscuridad, efectos capaces de observar el edifico a veces desde dentro y otras desde fuera.
7. CONCLUSIONES. El edificio respondió a sus propósitos colectivistas albergando una manera de habitar que promovía la organización social en las bases mineras. Su diseño incrementó la experiencia colectiva haciendo que sus residentes compartieran un mismo sistema espacial y funcional, y en consecuencia, cultural. Se socializaba así la educación moral entre el proletariado, el progreso y la modernidad.

El Chollín reúne en su diseño una gama de consideraciones vanguardistas que operan como condensadores sociales con los ejercicios perceptuales del promenade arquitectural.

Su complejo sistema circulatorio favoreció el autocontrol social de la comunidad y su uso como espacio de socialización vecinal. En lo ideológico, implica la conjunción de dos valores filosóficos y políticos: la ratificación de la estructura familiar como pilar de la clase trabajadora y al mismo tiempo, el enaltecimiento del individuo como hombre nuevo y pieza fundamental de colectivo socialista.

La configuración espacial y funcional del conjunto, y el enlace de sus relaciones, ha permitido sostener el sentido de pertenencia e identidad social de sus residentes. Ellos han podido extender en el tiempo un sentimiento de unidad en torno a un pasado común y un futuro por resolver. $\mathbf{\Delta e s}$

\section{REFERENCIAS}

Aguayo, P., Navarro, E., 1952. Arquitectura en Schwager. Seminario de título inédito. Universidad del Bio-Bio, 1993. (no está referenciada)

Astorquiza, O., Galleguillos, O., Cien años del carbón de Lota. Santiago de Chile. Editorial Zig-Zag.

Baltanás, J., 2005. Le Corbusier, promenades. Gustavo Gili, Barcelona, España.

El Mercurio de Antofagasta, el 18 de julio de 1939.

Fuentes, P., Mayorga, E., 2012. El edificio Chollin: Arquetipo de la promenade arquitectural en Chile. Arquitecturas del Sur, no 40, 2012, pp. 6-15.

Galaz-Mandakovic, D., 2011. Edificios Colectivos de la Caja del Seguro Obrero Obligatorio de Tocopilla, 1939-41. Movimiento Moderno, solución social. Emelnor Impresores, Antofagasta, Chile. (no está referenciada)

Garcés, E., 1999. Las ciudades del salitre. Editorial Origenes. (no está referenciada)

http://www.bubok.es/libros/211522/Edificios-Coletivos-de-la-Caja-del-Seguro-Obrero-Obligatorio-de-Tocopilla-193941-Movimiento-Moderno-solucion-social

http://www.coronel.cl/2011/07/puchoco-schwager.

http://www.ine.cl/canales/usuarios/cedoc_online/censos/pdf/censo_1940.pdf

http://www.youtube.com/watch?v=eDXOEOQLZVY

Inostroza, C., 2010. Schwager imágenes sociales inéditas. Consejo de la Cultura y las Artes Región del Bio-Bio.

Pérez, L., 2008. "El barrio Puchoco en Schwager, cuando la Industria construye paisaje cultural". Urbano, vol. 11, n 18, noviembre, 2008, pp. 47-58.

Secretaría ejecutiva desarrollo de Barrios/MINVU; Bustos Peñafiel, Mónica et al. Vivienda Social en Copropiedad. Memoria de Tipologías en condominios sociales, Santiago de Chile, mar., 2014.

Teige, K., 1933. "Le Probleme de L' Habitation Minimun", L'Architecture D' aujoud 'hui , n 5, jun, 1933, p. 45.

Teige, K., 2002. The Minimum Dwelling, MIT Press, 2002. 